\title{
Does the Fight Profile Interfere with Orthopedic Injuries in Brazilian Jiu-jitsu?
}

José Martins Juliano

Eustaquio $\mathbb{D D}^{1,2}$

Alberto Martins Fontoura

Borges (D) ${ }^{2}$

Lorena Souza Vilela $\mathbb{D D}^{2}$

Matheus Pizarro Carvalho

Gouveia $\mathbb{1}^{2}$

Amanda Laruzo Rabelo (iD ${ }^{2}$

Camila Cohen Kaleka $\mathbb{1}^{3}$

Pedro Debieux (1D)

Octávio Barbosa Neto (iD ${ }^{1}$

'Exercise Science, Health and Human Performance Research Group, Graduate Program in Physical Education, Federal University of Triângulo Mineiro (UFTM Universidade Federal do Triângulo Mineiro), Uberaba, MG, Brazil;

${ }^{2}$ Department of Orthopedics and

Traumatology, Mário Palmerio Hospital, University of Uberaba (UNIUBE -

Universidade de Uberaba), Uberaba, MG, Brazil; ${ }^{3}$ Knee Surgery Group, Hospital Israelita Albert Einstein, São Paulo, SP, Brazil; ${ }^{4}$ Knee Surgery and Arthroscopy Group, Federal University of São Paulo (UNIFESP - Universidade Federal de São Paulo), São Paulo, SP, Brazil

Correspondence: José Martins Juliano Eustaquio

Mário Palmerio Hospital, University of Uberaba (UNIUBE - Universidade de Uberaba), Av. Cecília Palmerio, s/n, Uberaba, MG, CEP: 38050175, Brazil Email zemartinsjuliano@hotmail.com; octavio.neto@uftm.edu.br
Purpose: To evaluate the prevalence and characteristics of orthopedic injuries associated with the technical-tactical profiles of Brazilian Jiu-Jitsu (BJJ) fighters, according to the fighters' graduation level (beginner and advanced).

Patients and Methods: Cross-sectional study, which included the participation of amateur and professional BJJ athletes, aged between 18 and 60 years and practitioners of the sport for at least six months. All answered a mixed self-reported morbidity questionnaire. Participants were divided into four groups, according to the technical-tactical profile in the fight (keeper and passer) and the fighter's graduation level (beginner and advanced), and also into four subgroups, divided by joining the groups in pairs above. Descriptive and analytical statistical procedures were used, with a level of statistical significance set at $5 \%(\mathrm{p}<0.05)$.

Results: A total of 198 participants were included in the study. There was a higher prevalence of musculoskeletal injuries in advanced fighters $(p<0.001)$, with no significant difference between the profiles of guard and passer fighters. Sprains were the most common type of injury in all studied groups and subgroups. The anatomical segments knee and shoulder, respectively, were the most affected in all groups, and both segments showed significant associations of the athletes in the advanced and guard groups.

Conclusion: The study showed important data for creation of specifics injury prevention protocols, through the higher prevalence of injuries in athletes of the advanced profile and in the segments of the knee and shoulder, with emphasis on the guard fighters.

Keywords: martial arts, sports injuries, orthopedics

\section{Introduction}

Brazilian Jiu-Jitsu (BJJ) is a fighting modality whose main objective is to immobilize the opponent through specific techniques until the opponent's submission (through twists, chokes and joint braces). ${ }^{1}$ These techniques are performed through intermittent efforts, in which quick actions and specific technical skills are required. ${ }^{2}$ Therefore, BJJ practitioners need good physical conditioning and satisfactory musculoskeletal support to defend or attack successfully. ${ }^{3}$

In BJJ there are two styles of fighters, in relation to the technical-tactical profile, the guard passing fighter (PF) and the guard playing fighter (GF) (Figure 1). The $\mathrm{PF}$, on the one hand, who stands a large part of the fight, performs offensive and explosive movements through attacks on the opponent. ${ }^{4}$ The GF, on the other hand, who keeps his hips on the ground, determines the combat cadence, through defense to the other fighter's attacks, mainly through isometric movements of the upper and lower limbs. ${ }^{4}$ 


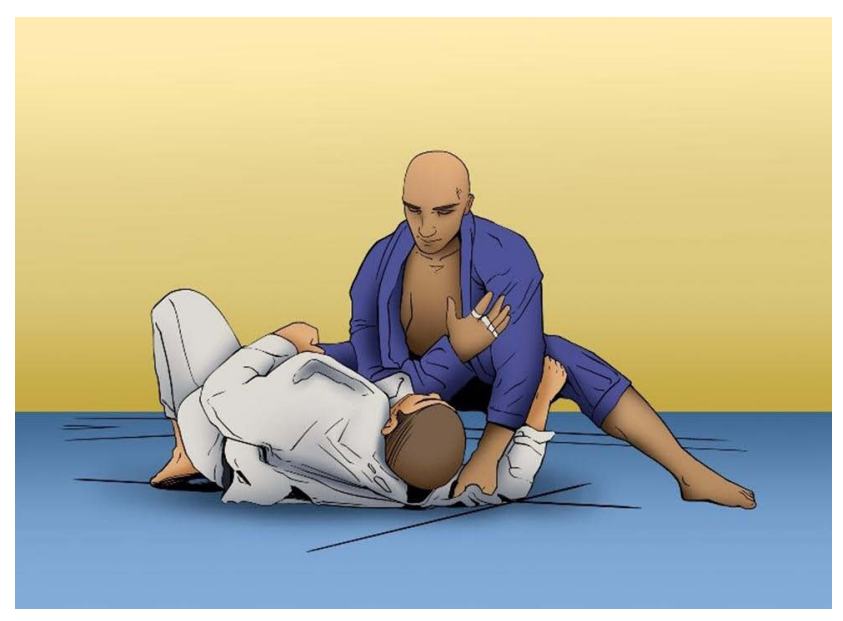

Figure I Technical-tactical profile in the BJJ: guard passing fighter (PF), with uniform blue, and the guard playing fighter (GF), with uniform white.

Fighters develop both positions early in the sport, but soon opt for one of the two styles. ${ }^{5}$ During combat, there will always be a dominant tactical profile, but that does not prevent the practitioner from interspersing with brief periods of fighting in the opposite profile.

The training intensities which were imposed by different combat positions are considerably different and can promote specific musculoskeletal adaptations. ${ }^{5}$ These morphofunctional differences between the two combat profiles and also between the different levels of fighter graduation (beginners and advanced) represent the athlete's specificity. In addition, in modern competitive sport (recreational or professional), there is an increase in physical and emotional loads and also in training volume, which exposes participants to the appearance of orthopedic injuries. ${ }^{6,7}$

Thus, it is necessary to develop more specific injury prevention protocols, according to each modality and its peculiarities. ${ }^{8}$ Knowing of the epidemiological characteristics of the sport and its most frequent injuries, according to the practitioner's profile, an essential measure to develop priorities for exercise planning and monitoring, in order to improve performance and prevent the onset of musculoskeletal injuries.

To date, there are no data in the literature about these characteristics stratified according to the fighter's profile in this modality. Therefore, this study aimed to evaluate the prevalence and characteristics of orthopedic injuries associated with technical-tactical profiles in the BJJ, according to the fighters' graduation level (beginner and advanced). Our hypothesis was that the GF and PF profiles, stratified or not by graduation level, have an influence on the epidemiological data of musculoskeletal injuries in the BJJ.

\section{Materials and Methods}

\section{Study Design}

Cross-sectional study carried out in BJJ academies duly registered with the Brazilian Confederation of BJJ. Sampling was by convenience (as it was a limited audience), using the "snowball" technique (Figure 2). The study was approved by the Research Ethics Committee of the Federal University of Triângulo Mineiro $\left(\mathrm{n}^{\mathrm{o}}\right.$ $3636261 / 2019$ ) and conducted in accordance with the principles set forth in the Helsinki Declaration. ${ }^{9}$

\section{Participants}

Professional adult athletes and BJJ amateurs, of both genders, BJJ practitioners for at least six months and with a well-defined fight profile (GF or PF) were included. All participants signed the Informed Consent Form. The exclusion criterion was filling out the questionnaire performed in the study in an incorrect or incomprehensible way.

Participants were initially divided into four groups, according to their graduation level (beginner and advanced) and technical-tactical profile in the fight (GF and PF). The beginning fighters were those who belonged to the white and blue belts and the advanced fighters were those belonging to the other belts. The technical-tactical profile was defined by both the fighter and the BJJ instructor. In cases where there were differences, the definition of the instructor prevailed. They were also divided into four subgroups, based on the previous groups and were divided into beginning GF (bGF), advanced GF (aGF), beginning PF (bPF) and advanced PF (aPF).

\section{Questionnaire}

Each participant answered an adapted mixed morbidity questionnaire, validated for use in sports traumatology ${ }^{10}$ and used in studies with similar methodologies, ${ }^{11,12}$ with proper explanation and supervision by a medical researcher of completion by someone responsible for the study. In addition to the injury history, there were questions regarding anthropometric characteristics, such as weight and height.

A three-year retroactive period of analysis of the lesions was adopted, in relation to the time to complete the questionnaire, which was stipulated by the researchers, since there are no data in the literature about the study period standardization in relation to previous injuries in martial arts. In team sports, injury assessments are 


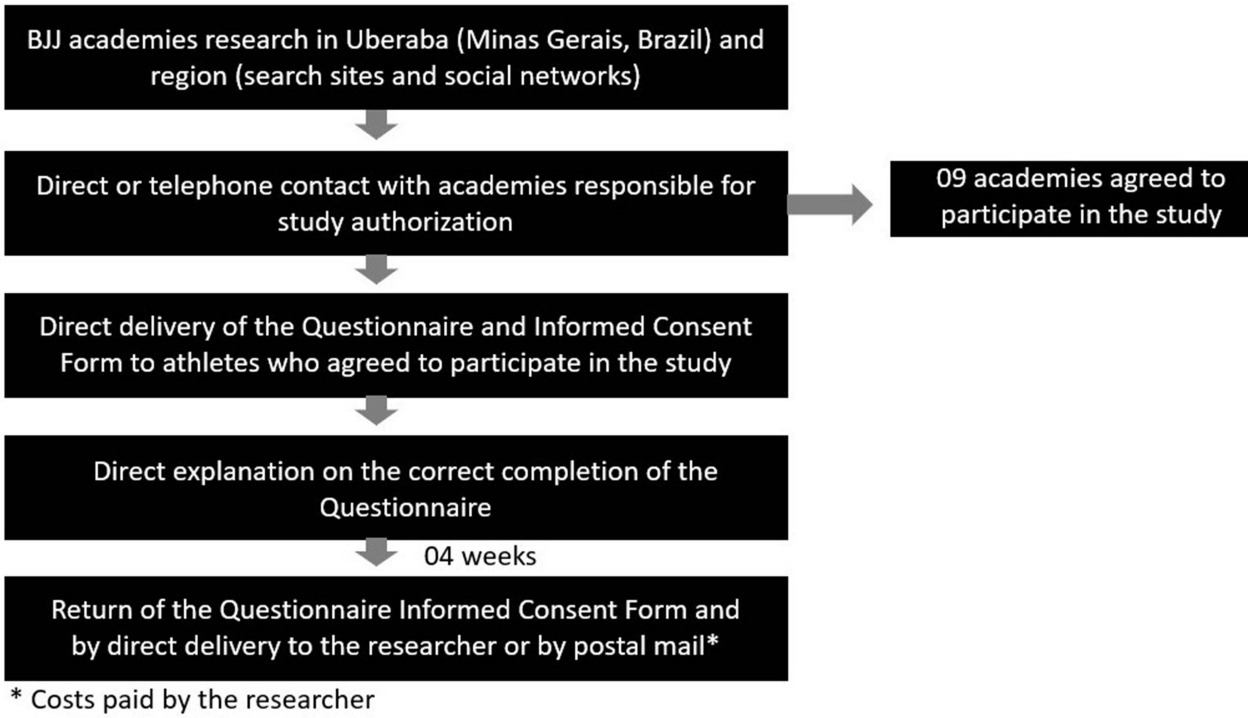

Figure 2 Representative flowchart of the study design.

generally carried out every season. However, in martial arts sports a longer period of evaluation is necessary, especially in sports with a limited number of practitioners.

\section{Orthopedic Injury Concept}

For standardization, we adopted a concept of injury already used in a previous study, ${ }^{13}$ in which it was considered as any pain or traumatic event caused by BJJ training and occasion training interruption for at least one week, or training modification for at least two weeks or a complaint serious enough to seek medical attention.

Only injuries resulting from training were considered, because not all athletes were competitors and, to calculate the prevalence of injuries in competitions, it would be necessary to know the risk exposure rate to injuries (number of competitions, time of each combat, among others), a fact that cannot be reliably carried out in this study with the current methodology employed.

The injuries were stratified in contusion, nonspecific pain (pain of non-traumatic origin, such as tendinopathies), dislocation, muscle injury, fracture and sprain. About anatomical locations of the injuries, all lower and upper limb segments were considered, in addition to the cervical and lumbar spines, ribs and neck (muscle injuries in this segment).

The orthopedic injury was considered adequate to be mentioned in the questionnaire only when it occurred when the athlete presented the dominant fight profile mentioned in the study. As already mentioned, during combat, an athlete can assume more than one tactical fight profile, but there will always be a dominant profile.

\section{Statistical Analysis}

Data were collected and processed using Excel ${ }^{\circledR}$ and SigmaStat ${ }^{\circledR} 2.0$ (GraphPad Software Jandel, SPSS, Chicago, IL, USA). It was recommended the prevalence calculation of injuries every 1000 training hours/athlete/ year, because they are more objective data for comparisons in future studies.

The Kolmogorov-Smirnov test was used to verify the normality of data distribution. Continuous variables with normal distribution were presented as average and standard deviation and those that did not have normal distribution were presented as a median and interquartile interval (IQR; 25th and 75th percentiles). Categorical variables were presented as percentages.

For comparisons of the quantitative variables, in relation to the graduation level (beginner and advanced) and the technical-tactical profile (GF and PF), the unpaired Student's $t$-test (two-tailed) for parametric data or the Mann-Whitney for nonparametric data. The Chi-square test or Fisher's exact test was used to assess qualitative variables. For the quantitative parametric analyses of the four subgroups, the two-way ANOVA test (graduation and profile) was used with the Tukey post hoc test to identify differences in groups and their locations, respectively. Nonparametric data were analyzed using the KruskalWallis test, followed by Dunn's post hoc test. The level of statistical significance was set at $5 \%(\mathrm{p}<0.05)$. 


\section{Results}

After collecting the information and completing the database using the applied questionnaires, of a total of 217 initial participants, 198 (9\% exclusion rate) were included in the present study, with $90.9 \%$ male and mean age of $33.2 \pm 8.6$ years. Higher BMI values were observed in advanced athletes and guard passing fighters (Table 1).

In prevalence analysis of musculoskeletal injuries for every 1000 hours of BJJ training/athlete/year, higher rates were observed for advanced (1.15) and guard passing (1.08) groups and for the aGF subgroup (1.23), followed by bPF (1.11) (Table 2).

In bivariate analysis of injuries mean, there was a significant difference in injuries amount between the advanced and beginner groups $(p<0.001)$. When considering the four subgroups of fighters, a significant difference was observed between them $(\mathrm{p}<0.001)$ and, in the pair analysis, this difference was in favor of aGF in relation to bGF $(p<0.001)$ and to bPF $(p=0.006)$ and in favor of aPF in relation to bGF $(p=0.001)$ (Table 2$)$.

The groups of participants had a previous history of all injuries types considered in this study. Sprain was the most common injury type in all four study groups, with statistical significance for advanced athletes, compared to beginners $(p=0.04)$ (Table 3$)$. As for the athletes subgroups, it was observed that sprain was also the most common injury and there was a statistically significant association in this injury type, in favor of the aPF subgroup $(\mathrm{p}=0.01)$ (Table 3$)$.

The anatomical segments knee and shoulder were the most affected in all study groups, with significant associations in favor of advanced athletes $(p<0.001$ for knee and

Table I Demographic Characteristics of the BJJ Fighters Participating in the Study, According to the Technical-Tactical Profile in the Fight

\begin{tabular}{|c|c|c|c|c|c|c|c|}
\hline & \multirow{3}{*}{$\begin{array}{c}\text { Total } \\
(n=198)\end{array}$} & \multicolumn{3}{|c|}{ BJJ Graduation } & \multicolumn{3}{|c|}{ Technical-Tactical Profile } \\
\hline & & Beginner & Advanced & p-value & GF & PF & p-value \\
\hline & & $(n=I \mid 3)$ & $(n=85)$ & & $(n=105)$ & $(n=93)$ & \\
\hline Age (years) & $33.2 \pm 8.6$ & $31.1 \pm 7.8$ & $36.0 \pm 8.9$ & $<0.001^{\mathrm{a}}$ & $32.0 \pm 9.3$ & $34.5 \pm 7.7$ & $0.021^{\mathrm{a}}$ \\
\hline Male n (\%) & $180(90.9)$ & $97(85.8)$ & $83(97.6)$ & $0.332^{c}$ & $93(88.6)$ & $87(93.5)$ & $0.709^{c}$ \\
\hline Female $\mathrm{n}(\%)$ & $18(9.1)$ & $16(14.2)$ & $2(2.4)$ & $0.002^{c}$ & $12(11.4)$ & $6(6.5)$ & $0.238^{c}$ \\
\hline Body mass $(\mathrm{Kg})$ & $83.0 \pm 15.1$ & $82.2 \pm 14.1$ & $84.2 \pm 16.3$ & $0.174^{\mathrm{a}}$ & $79.0[70.0-89,0]$ & $85.0[77.0-97,0]$ & $<0.001^{b}$ \\
\hline BMI (Kg/m2) & $31.4 \pm 4.9$ & $26.3[24.2-29.4]$ & 26.9 [24.9-30.0] & $0.094^{b}$ & $25.8[23.7-28.7]$ & $27.7[25.4-30.8]$ & $<0.001^{b}$ \\
\hline Practice time of BJJ (years) & $5.8 \pm 5.6$ & $2.0[1.0-3.0]$ & $8.5[5.5-13.0]$ & $<0.00 I^{b}$ & $6.1 \pm 6.1$ & $5.4 \pm 5.1$ & $0.433^{\mathrm{a}}$ \\
\hline
\end{tabular}

Notes: Values are presented as $\mathrm{n}(\%)$, means \pm standard deviation (SD), medians (25th and 75th percentiles). ap value for comparisons between groups by the $t$-test for independent samples. bp value for comparisons between groups using the Mann-Whitney U-test. c $p$ value for comparisons between groups using the Chi-square test. Abbreviations: BJJ, Brazilian Jiu-Jitsu; GF, guard playing fighter; PF, guard passing fighter; BMI, body mass index.

Table 2 Analysis of the Prevalence (Every 1000 Hours of BJJ/Athlete/Year) and the Association of Musculoskeletal Injuries in Training, According to the Level of Graduation (Beginners and Advanced), Technical-Tactical Profile in the Fight (Guard Playing Fighter and Guard Passing Fighter) and Subgroups (aGF, aPF, bGF, bPF) of BJJ Fighters

\begin{tabular}{|c|c|c|c|c|c|c|}
\hline $\begin{array}{l}\text { BJJ } \\
\text { Fighters }\end{array}$ & Injuries & $\begin{array}{l}\text { BJJ Training Time } \\
\text { (Hours/Year) }\end{array}$ & $\begin{array}{c}\text { Prevalence of Injuries (1000 } \\
\text { Hours/ Athlete/Year) }\end{array}$ & $\begin{array}{c}\text { Average } \\
\text { Injuries } \pm \text { SD }\end{array}$ & $\mathrm{Cl}$ & $\begin{array}{l}\text { p-value (for the } \\
\text { Injuries Average) }\end{array}$ \\
\hline Advanced & 113 & 32,656 & 1,15 & $1.33 \pm 1.11$ & I,09-1.57 & $<0.00 \mathrm{la}$ \\
\hline Beginners & 18 & 30,472 & 0.85 & $0.69 \pm 1.01$ & $0.50-0.88$ & \\
\hline GF & 99 & 34,632 & 0.95 & $0.94 \pm 1.09$ & $0.73-1.15$ & $0.779 a$ \\
\hline PF & 92 & 28,496 & 1.08 & $0.99 \pm 1.11$ & $0.76-1.22$ & \\
\hline aGF & 71 & 19,188 & 1.23 & $1.48 \pm 1.13^{*}$ & $1.15-1.81$ & $<0.00 \mathrm{lb}$ \\
\hline aPF & 42 & 13,468 & 1.04 & $1.14 \pm 1.067$ & $0.78-1.49$ & \\
\hline bGF & 28 & 15,444 & 0.60 & $0.49 \pm 0.83$ & $0.27-0.7$ I & \\
\hline bPF & 50 & 15,028 & 1.11 & $0.89 \pm 1.14$ & $0.58-1.19$ & \\
\hline
\end{tabular}

Notes: ${ }^{*} p<0.00$ I vs bGF; $p=0.006$ vs aGF; $¥ p=0.00$ I vs bGF. ap value for comparisons between groups using the Mann-Whitney $U$-test. bp value for comparisons between groups by the Kruskal-Wallis/Dunn post hoc test.

Abbreviations: BJ], Brazilian Jiu-jitsu; $\mathrm{Cl}$, confidence interval; SD, standard deviation; bGF, beginner guard playing fighter; aGF, advanced guard playing fighter; bPF, beginner guard passing fighter; aPF, advanced guard passing fighter. 


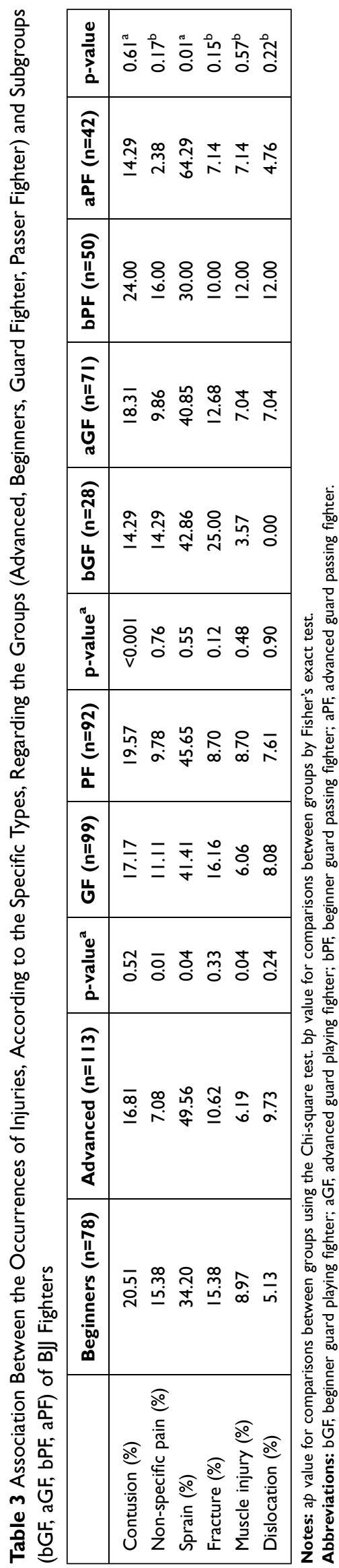

$\mathrm{p}=0.04$ for shoulder) and GF $(\mathrm{p}=0.04$ for knee and shoulder) (Figure 3).

\section{Discussion}

The main findings of this study were that advanced athletes had a higher prevalence of orthopedics injuries and, in all groups and subgroups studied, sprain was the main type of injury and the knee was the most common anatomical location. Besides that, there was a statistically superior association of knee and shoulder injuries in GF group athletes, compared to the PF group.

It is worth mentioning that epidemiological studies in sports medicine lack methodological standardization, requiring an attempt to create better assessment methods. ${ }^{14,15}$ The standardization of epidemiological terms and calculations, for example, the prevalence analysis based on 1000 hours of training/athlete/year, helps to improve one's knowledge about the sports injuries characteristics. ${ }^{14}$

At least theoretically, the existing differences between the physical standards of PF and GF fighters may justify changes in the BJJ injury profile. On the one hand, PF fighters are stronger and/ or heavier (higher BMI, as observed in the current study) and benefit from this biotype to generate greater mechanical overload on their opponents. $^{5}$

On the other hand, GF fighters are generally larger and more flexible, which gives biomechanical advantages in lever movements. ${ }^{5}$ In addition, they perform isometric strength in a longer time in the fight ${ }^{5,16}$ and generally require a high level of strength and flexibility to apply various techniques, that demand the fighter to push or pull the opponent to prepare and trying a submission. ${ }^{17-20}$

About the anatomical locations most affected by musculoskeletal injuries, a previous study with similar methodology, showed that anatomical locations of injuries were more common in the knee (20.8\%), followed by the shoulder $(12.1 \%) .{ }^{21}$ This predominance, also observed in the current study with GF profile (both beginners and advanced) suggests that guard playing athletes are more subjected to rotational movements, as occurs in the joint keys techniques, mainly because they spend a large part of the fight performing defense maneuvers against the attack of guard passing fighters.

Although it was not the focus of this study, muscle imbalances between the hamstrings and quadriceps and the external and internal shoulder rotators, mainly because of the little dominant quadriceps and medial rotators of the shoulder, may be one of the possible mechanisms 


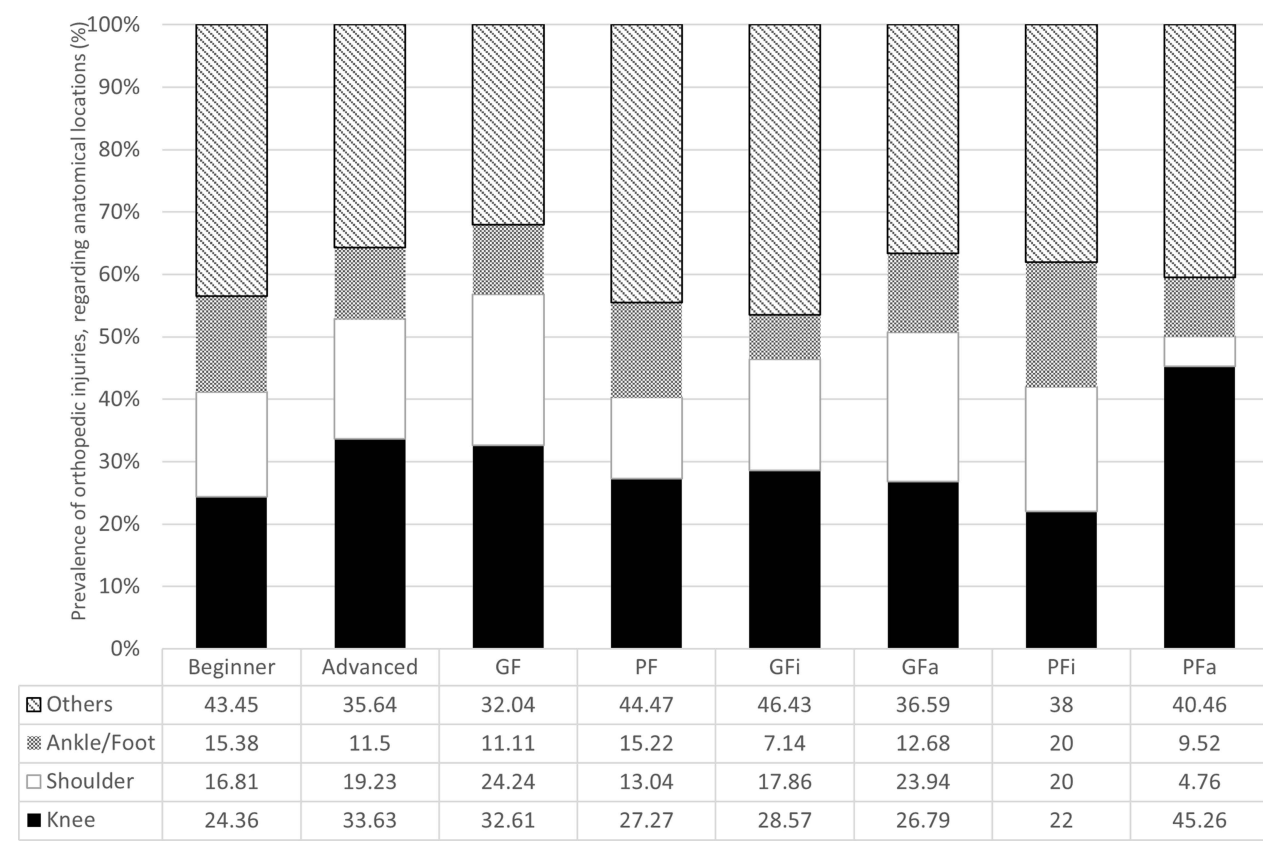

Figure 3 Association between the locations and the occurrences of injuries according to the level of graduation (beginner and advanced), the technical-tactical profile and of

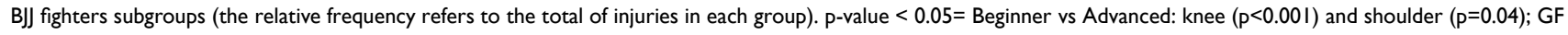
vs PF: knee $(p=0.04)$ and shoulder $(p=0.04)$.

Note: Lesions classified as "Others" occurred in 10 different anatomical locations.

underlying the injuries sports on the knee ${ }^{22}$ and shoulder, ${ }^{23}$ respectively. Therefore, strength imbalances associated with high intensity efforts, through blows that combine different techniques, may be related to the high rates of joint injuries in BJJ fighters.

The intrinsic stability of the joint is another factor to be considered regarding the most common location of injuries. In this sense, the shoulder is the most mobile joint in the body, ${ }^{23}$ and consequently, has the most compromised stability.

Among the subgroups of the study, the proportions of ankle/ foot injuries in guard passing fighters has stand out, both advanced and beginners. These fighters, making attacks on their opponent in a standing position and often based on explosive movements, with frequent changes of position and support on the ground, they are really more prone to injuries in the distal segment of the lower limb.

As for the level of graduation of the fighters, the literature shows that the more experienced ones have a higher prevalence of injuries compared to beginners, ${ }^{24,25}$ as observed in the current study. The main factors related to this finding are, in relation to advanced athletes, greater exposure due to the greater volume of training, combats with greater competitive intensity and greater prevalence of previous injuries, which increase the chance of recurrence.
This recurrence of injuries is relevant in all sporting modalities ${ }^{26,27}$ and, in fighting modalities, which reflects generally ineffective treatments, often performed without the regular supervision of a health professional, and the early return to sport, which is a harmful factor as it involves both the biomechanical limitation of the segment and the typical kinesiophobia observed after an injury. ${ }^{28}$ In this study, it was observed that, among advanced athletes, $20 \%$ of the injuries were recurrent, with emphasis on the knee joints (55\%) and ankle/foot (20\%).

Regarding beginners athletes, it is worth noting that, due to the technical requirements of the sport that guard passing fighters perform plyometric attacks, it would be prudent for them to start the BJJ practice in a mixed or guard playing fighter profile, as this biomechanical valence is rarely found ineffectively in an athlete at the beginning of sports practice. As soon as the adaptation and specific training periods ended, the athletes who chose to assume the LP profile would go through the transition process.

The main limitations of this study were its cross-sectional design and gender bias, quite common in martial arts studies. ${ }^{11}$ To minimize the potential recall bias of participants, the researchers chose to stipulate the three years prior to the interview as a limit for reporting injuries. In addition, some injuries reported in the questionnaire were not diagnosed by a medical team, however, there was supervision 
by a medical researcher when filling out the questionnaire, which limited any misunderstandings. Because there is a limited audience of BJJ athletes and few literature data regarding the topic, it became necessary to consider all injuries occurred that had in the studied period.

Despite these limitations, this epidemiological study provided important data about characteristics of the musculoskeletal injuries according to the BJJ technical-tactical profile. There are no studies that address the characteristics of these injuries in terms of the tactical specificities of practitioners.

These data will be important for further studies, related to performance improvement and injury prevention, according to the specificity of the different profiles of Jiu-Jitsu fighters and the epidemiological characteristics of the injuries described in this article. In addition, in order to help prevent injuries, supervision by coaches during training is suggested, with emphasis on physical work focused on the biomechanical characteristics mentioned above, in addition to medical supervision before and after competitions.

\section{Conclusion}

The study showed a higher prevalence of orthopedic injuries in athletes with advanced profile and in anatomical segments that are considered potentially unstable in the dynamics of the BJJ fight, such as the knee and shoulder, with emphasis on guard-playing fighters. These epidemiological characteristics should be considered when designing training and injury prevention protocols.

\section{Funding}

This article was not funded.

\section{Disclosure}

No potential conflicts of interest for this work were reported by the authors.

\section{References}

1. International Brazilian Jiu- Jitsu Federation. Book of Rules; January, 2021. Available from: https://cbjj.com.br/books-videos. Accessed August 15, 2021.

2. Andreato LV, Julio UF, Panissa VLG, et al. Brazilian jiu-jitsu simulated competition. Part II: physical performance, time-motion, technical-tactical analyses and perceptual responses. J Strength Cond Res. 2015;29:2015-2025.

3. Andreato LV, Lara FJD, Andrade A, Branco BHM. Physical and physiological profiles of Brazilian jiu-jitsu athletes: a systematic review. Sports Med Open. 2017;3(1):1-17. doi:10.1186/s40798-0160069-5
4. Báez E, Franchini E, Ramírez-Campillo R, et al. Anthropometric characteristics of top-class Brazilian Jiu Jitsu athletes: role of fighting style. Int $J$ Morphol. 2014;32:1043-1050. doi:10.4067/S071795022014000300048

5. Lima PO, Lima AA, Coelho AC, et al. Biomechanical differences in Brazilian Jiu-Jitsu athletes: the role of combat style. Int J Sports Phys Ther. 2017;12:67-74.

6. Stephenson C, Rossheim ME. Brazilian jiu jitsu, judo, and mixed martial arts injuries presenting to United States emergency departments, 2008-2015. J Prim Prev. 2018;39(5):421-435. doi:10.1007/ s10935-018-0518-7

7. Gabbett TJ. The training-injury prevention paradox: should athletes be training smarter and harder? Br J Sports Med. 2016;50(5):273280. doi:10.1136/bjsports-2015-095788

8. Quatman CE, Quatman CC, Hewett TE. Prediction and prevention of musculoskeletal injury: a paradigm shift in methodology. Br J Sports Med. 2009;43(14):1100-1107. doi:10.1136/bjsm.2009.065482

9. World Medical Association. World Medical Association Declaration of Helsinki: ethical principles for medical research involving human subjects. JAMA. 2013;310(20):2191-2194. doi:10.1001/jama.2013.281053

10. Pastre CM, Carvalho Filho G, Monteiro HL, Neto Júnior N, Padovani CR. Sports injuries in athletics: comparison between own information in medical records and corporate morbidity surveys. Rev Bras Med Esporte. 2004;10(1):1-8. doi:10.1590/S1517-86922004000100001

11. Das Graças D, Nakamura L, Barbosa FSS, Martinez PF, Reis FA, Oliveira-Junior SA. Could current factors be associated with retrospective sports injuries in BJJ? A cross-sectional study. BMC Sports Sci Med Rehabil. 2017;9(1):1-10. doi:10.1186/s13102-017-0080-2

12. Nery LC. Prevalence of musculoskeletal injuries in Jiu-Jitsu competitors: a cross-sectional study [Master's Thesis]. São Paulo, SP: University City of São Paulo; 2014.

13. Weisenthal BM, Beck CA, Maloney MD, DeHaven KE, Giordano BD. Injury rate and patterns among CrossFit athletes. Orthop J Sports Med. 2014;2(4):2325967114531177. doi:10.1177/2325967114531177

14. Bahr R, Clarsen B, Derman W, et al. International olympic committee consensus statement: methods for recording and reporting of epidemiological data on injury and illness in sport 2020 (including STROBE Extension for Sport Injury and Illness Surveillance (STROBE-SIIS)). Br J Sports Med. 2020;54(7):372-389. doi:10. 1136/bjsports-2019-101969

15. Orchard JW, Meeuwisse W, Derman W, et al. Sport Medicine Diagnostic Coding System (SMDCS) and the Orchard Sports Injury and Illness Classification System (OSIICS): revised 2020 consensus versions. $B r \quad J$ Sports Med. 2020;54(7):397-401. doi:10.1136/ bjsports-2019-101921

16. Sousa DF, Eustaquio JMJ, Marocolo M, Mota GR, Neto OB. Cardiac autonomic alterations in different tactical profiles of Brazilian Jiu Jitsu. Rev Bras Med Esporte. 2020;26(3):196-200. doi:10.1590/ 1517-869220202603216617

17. Andreato LV, Franchini E, Moraes SMF, et al. Physiological and technical-tactical analysis in Brazilian jiu-jitsu competition. Asian $J$ Sports Med. 2013;4(2):137-143. doi:10.5812/asjsm.34496

18. Coswig VS, Neves AHS, Del Vecchio FB. Effects of duration practice in biochemical, hormonal and hematological parameters of people who practice Brazilian jiu-jitsu. Rev Andal Med Deporte. 2013;6 (1):17-23. doi:10.1016/S1888-7546(13)70030-3

19. Reis FJJ, Dias MD, Newlands F, Meziat-Filho N, Macedo AR. Chronic low back pain and disability in Brazilian jiu-jitsu athletes. Phys Ther Sport. 2015;16:340-343.

20. Villar R, Gillis J, Santana G, Pinheiro DS, Almeida AL. Association between anaerobic metabolic demands during simulated Brazilian Jiu-Jitsu combat and specific Jiu-Jitsu anaerobic performance test. $J$ Strength Cond Res. 2018;32:432-440.

21. Moriarty C, Charnoff J, Felix ER. Injury rate and pattern among Brazilian jiu-jitsu practitioners: a survey study. Phys Ther Sport. 2019;39:107-113. doi:10.1016/j.ptsp.2019.06.012 
22. Croisier JL, Ganteaume S, Binet J, Genty M, Ferret JM. Strength imbalances and prevention of hamstring injury in professional soccer players: a prospective study. Am J Sports Med. 2008;36(8):14691475. doi:10.1177/0363546508316764

23. Edouard P, Degache F, Oullion R, Plessis JY, Gleizes-Cervera S, Calmels P. Shoulder strength imbalances as injury risk in handball. Int J Sports Med. 2013;34(7):654-660. doi:10.1055/s-0032-1312587

24. Silva Junior JN, Kons RL, Dellagrana RA, Detanico D. Injury prevalence in Brazilian jiu-jitsu athletes: comparison between different competitive levels. Rev Bras Cineantropom Desempenho Hum. 2018;20(3):280-289. doi:10.5007/1980-0037.2018v20n3p280

25. Agel J, Ransone J, Dick R, Oppliger R, Marshall SW. Descriptive epidemiology of collegiate men's wrestling injuries: National Collegiate Athletic Association Injury Surveillance System, 1988-1989 through 2003-2004. J Athl Train. 2007;42:303-310.
26. Blanch P, Gabbett TJ. Has the athlete trained enough to return to play safely? The acute: chronic workload ratio permits clinicians to quantify a player's risk of subsequent injury. Br J Sports Med. 2016;50 (8):471-475. Erratum in: Br J Sports Med. 2019;53(18):e6. PMID: 26701923. doi:10.1136/bjsports-2015-095445

27. Ishøi L, Krommes K, Husted RS, Juhl CB, Thorborg K. Diagnosis, prevention and treatment of common lower extremity muscle injuries in sport - grading the evidence: a statement paper commissioned by the Danish Society of Sports Physical Therapy (DSSF). Br J Sports Med. 2020;54(9):528-537. doi:10.1136/bjsports-2019101228

28. Hsu CJ, Meierbachtol A, George SZ, Chmielewski TL. Fear of Reinjury in Athletes. Sports Health. 2017;9(2):162-167. doi:10.11 77/1941738116666813

\section{Publish your work in this journal}

Open Access Journal of Sports Medicine is an international, peerreviewed, open access journal publishing original research, reports, reviews and commentaries on all areas of sports medicine. The manuscript management system is completely online and includes a very quick and fair peer-review system. Visit http://www.dovepress. com/testimonials.php to read real quotes from published authors. 